University of Massachusetts Amherst

From the SelectedWorks of Elizabeth L. Krause

2022

Out of Place: Everyday Forms of Marginalization, Racism, and Resistance among Chinese Migrants in Italy

Elizabeth L. Krause

Ying Li 


\section{Out of place: everyday forms of marginalization, racism, and resistance among Chinese migrants in Italy}

\section{Elizabeth L. Krause \& Ying Li}

To cite this article: Elizabeth L. Krause \& Ying Li (2020): Out of place: everyday forms of marginalization, racism, and resistance among Chinese migrants in Italy, Journal of Ethnic and Migration Studies, DOI: 10.1080/1369183X.2020.1801399

To link to this article: https://doi.org/10.1080/1369183X.2020.1801399

\section{冓 Published online: 04 Aug 2020.}

Submit your article to this journal $\widetilde{ }$

Q View related articles $\sqsubset$

View Crossmark data $\asymp$ 


\title{
Out of place: everyday forms of marginalization, racism, and resistance among Chinese migrants in Italy
}

\author{
Elizabeth L. Krause and Ying Li \\ Department of Anthropology, University of Massachusetts Amherst, Amherst, MA, USA
}

\begin{abstract}
This paper develops theories of place in relation to migration to argue that the diasporic population of Chinese migrants in Prato, Italy, live not only 'out of place' due in no small part to marginalisation and racism, but also live 'in place' as they resist and make meaning from experiences and interactions with particular places. We argue that place-based dynamics occurring in urban spaces such as Prato can best be understood in the context of a globalised fashion industry and the hegemony of global supply chains. We develop and extend the meanings of 'out of place' to show that migrants are doubly marginalised. We suggest that their conceptions of place reveal unexpected ways in which they live at the margins of society and not only experience racism but resist it. This paper integrates three different types of ethnographic data: (1) unstructured, in the form of ethnographic noticing; (2) structured, in the form of free listing; and (3) semistructured in the form of interviewing. Combining these methods strengthens our argument for the importance of place-based experiential knowledge. We offer a critical lens on a globalising Europe and expose particular modes of marginalisation, racism, and resistance. We end with possible applications.
\end{abstract}

\section{ARTICLE HISTORY}

Received 3 March 2020

Accepted 20 July 2020

\section{KEYWORDS}

Place; ethnography; free-list interviews; marginalisation; racism; globalisation; Chinese migrants; fast fashion

\section{Introduction}

Migration categories suggest movement from place to place. In light of Europe's 'migration crisis,' scholars have challenged fundamental categories that differentiate between refugees and migrants due to the ways those categories divide and discriminate (Crawley and Skleparis 2018; Ticktin 2011). Others have problematised assumptions that migration occurs between two fixed places (Collyer and de Haas 2012). Labels of 'migrant,' 'immigrant,' 'undocumented,' or 'illegal' in various discursive ways mark people, assumed to be on the move, as different and as not quite belonging to the place where they are living. Drawing attention to labels and questioning categories opens conceptual space for inquiries about the relationship between migrants and place. The paper offers findings from our research into the concrete cultural domain of 'place' among diasporic Chinese living in Prato, Italy, a factory-city known for its concentration of Chinese migrant workers and entrepreneurs in the fast-fashion industry. 
Oftentimes, when marginalised or subaltern members of a given population are involved, local forms of knowledge are considered unofficial, incoherent, of low value, and thus disqualified (Foucault 1980). As anthropologists, we integrate ethnographic methods because of our commitment to understand how people across spectrums of power in a given society put things together and think about them. We build on scholarship in contemporary Italy that explains the 'extraordinary economic success' of Chinese migrants and parse to what degree they 'thrive in alien surroundings' (Chen 2015, 112). Our focus on how Chinese migrants valued different places allowed us to gain understanding into their place-based experiential knowledge. We argue that the diasporic population of Chinese migrants not only live 'out of place' due in no small part to marginalisation and racism, but they are also 'in place' as they resist and make meaning from experiences and interactions with particular places.

The structure of the paper is organised around the following: setting, literature, methods, findings, and discussion. A section on 'Setting' provides ethnographic context and reviews the history of migration to an industrial district in the greater metropolitan area of central Tuscany. This setting serves as the backdrop for our argument that migrants' interactions with place signifies belonging and identity. Mindful of the idea that identities are relational (Pandolf 2007), our investigation shows the ways that certain places are meaningful to research participants. A section titled 'Out of Place' situates the study in literature related to place especially as regards migration. In the section 'Ethnographic Methods: Integrating Approaches,' we spell out ethnographic data collected from the authors' fieldwork. This section explains how our team-based research design confronted challenges and enabled our findings. We discuss our findings in a core section, 'Making Place-Based Knowledge: An Overview of Findings,' which is subdivided into two parts: the first based on quantitative results from free-list interviews, the second on qualitative results in narrative form from semi-structured interviews. We argue that these findings play a significant and critical role in producing and transforming knowledge connected to marginalisation, racism, and resistance among a diasporic population. The paper concludes with a discussion of 'Migrants in Place' as well as suggestions for future research and applications.

\section{Setting}

The factory-city of Prato, 20 miles north of Florence, served as an ethnographic laboratory for investigating conditions of globalisation. The city offers a microcosm of latecapitalist development and migration. Newcomers were drawn to Prato as a newmoneyed city after World War II. People in search of possibilities migrated initially from the nearby countryside and later from more distant points of origin, suggesting three migratory phases: regional, national, and transnational. On the Western side of the city, San Paolo and Macrolotto Zero became landing points, or zones of transition (Bressan and Cambini 2009). In these adjacent neighbourhoods, residential apartments and manufacturing structures intermingle. A chaotic layout dominates with narrow streets and structures squeezed into tight spaces. The renowned urban planner Bernardo Secchi (1996) coined the phrase città-fabbrica in the 1990s to reflect his vision of mixité, a planning principle that advances a vibrant mixing of different social and cultural elements. 
At the time of this writing, Prato boasted a total population of 195,089, of which 42,371 , or $22 \%$, were classified as stranieri, or foreign residents, compared with $8.8 \%$ foreign residents nationwide (Istat 2020). Of the total registered foreigners, registered Chinese migrants total 24,906, more than 50\%. When overseas Chinese without residency permits are included, estimates often double those on record. These ratios have won the city various popular designations, such as Europe's No. 1 multicultural city (Brandi and Sabatini 2012; Ufficio di Statistica del Comune di Prato 2019).

Indeed, in the past two decades, the factory-city, famous for its sprawling industrial district, has come to host one of Europe's largest overseas Chinese communities. Their arrival is deeply linked with a globalised story of industrial decline and niche rise. At the height of Prato's industrial productivity, in the late 1970s and early 1980s, the city and its environs accounted for nearly a quarter of the nation's textile output (Becattini 2001). The Made In Italy brand earned a global reputation not only for its quality but also for its alternative mode of organisation given the dominance of small and medium-sized firms famous for their flexibility (Piore and Sabel 1986). Crisis transformed the industrial district as globalisation pressures witnessed mergers, outsourcing, and closures. The geographer Tu Lan, who conducted field-based research among Chinese firms in Prato, describes global shifts in the apparel industry as 'one of the major economic conditions' along with 'a crisis of capitalist accumulation' for the rise of pronto moda, or fast-fashion, in Prato. He reminds that during Prato's 'heyday,' textile firms totalled 10,000 - a number that plummeted to 2,979, or 68\%, in the decade between 1991 and 2001 (Lan 2015, 161-163). It is precisely in this context that the Chinese fast-fashion niche emerged, a reflection of global value chains as regards the fashion industry. Most immigrants arrived initially to produce low-cost clothing items. Some provided subcontracted labour for luxury Italian fashion brands (Clean Clothes Campaign 2014). Many have taken advantage of opportunities to open their own firms: one in three businesses in Prato as of 2019 were owned by individuals of foreign nationality (Camera di Commercio 2020).

The particular conditions of fast-fashion converged to transform Prato and its province into a hotbed of transnational entrepreneurial activity. Active Chinese-managed firms in 2019 totalled 6,263, according to Prato Chamber of Commerce data (Camera di Commercio 2020). These data demonstrate the prevalence of Chinese business activity. The phenomenon permeates the productive apparatus. Chinese manufacturing alone represents $55.4 \%$ of the provincial industrial sector. Although the majority, about 3,800 firms, continue to be counted in the category of confezioni, i.e. cut-and-sew or garment-production work, the report notes a 'significant presence' in textiles, where Chinese now operate 420 factories, representing about $22 \%$ of the sector. Particularly noteworthy is a trend toward diversification as Chinese firms grow in other sectors, such as small shops as well as services, including hotels, bars, restaurants, and real estate. Similar to Italian firms, most Chinese firms are small, typically family-owned, with fewer than 10 workers.

Our ethnographic research confirmed that many migrants arrive with debt as well as aspirations to pay it off and own a business. To that end, they have embraced flexibility that manifests in self-exploitation. Fast fashion requires a particularly demanding business model: design, production, and sales phases are 'so tight' as to overlap (Dei Ottati and Cologna 2015, 42). Fast fashion falls within the category of readymade clothing produced to a standard rather than custom tailored. Thus, fast fashion has a 'just-in-time' rhythm 
that shapes conditions for producers, retailers, and consumers (Reinach 2005). Our ethnographic research confirmed that the fast-fashion model requires that workers work on demand. This means long shifts, up to 16 or $18 \mathrm{~h}$, and often at night, squeezing in sleep during the day. Sewing in workshops without temperature controls is common, making for a dank and cold environment in the winter and a blistering hot one come summer. Many parents send their babies back to China to have relatives care for them and thus underwrite capitalist value (Krause and Bressan 2018). Manufacturing apparel has long been an 'imperfect industry,' (Entwistle 2000, 212) based on exploitation, inequality, struggle, and even tragedy.

The economic dynamics in Prato in the early 2000s led to Italian accusations of unfair competition as Chinese came onto the scene, some Italian factories moved overseas and others sought cheaper subcontractors in niches such as sweatermaking, garment or accessory production. In our interviews, Chinese fast-fashion owners and workers acknowledged fierce competition among the migrant workers themselves after the 2008 global financial crisis. The diasporic development along with the globalisation of fashion over time has disrupted identities associated with makers of the Made in Italy brand (Rofel and Yanagisako 2019). The size and characteristics of the Chinese population in Prato in the recent past resulted in their living marginalised lives characterised by minimal relations with Italian civic life (Bracci 2012). To understand this dynamic, Lan $(2015,166)$ points to a 'double exclusion' that involves Italian immigration policies, especially related to taxes and amnesties, and Chinese social norms, connected to constraints and motivations. At the same time, it is important to underscore initiatives of Chinese associations and activists, ranging from protests against factory inspections to acts of pandemic solidarity (see Krause and Bressan 2020). Changing signs of social inclusion have evolved over the past three decades. Heterogeneity in terms of occupation and socioeconomic stratification have come to characterise a mobile Chinese population with a deepening history and active youth associations and citizens serving in politics. Furthermore, recognition of structural and temporal similarities - which an Italian sweatermaker who migrated from rural Tuscany expressed during our research as ' $i$ cinesi siamo noi,' or, 'we are the Chinese' (Krause 2018, 123) - has led some Italians to embrace empathic outlooks toward the transnational migrants (Raffaetà and Baldassar 2015).

The demographic impact has been noteworthy in many contexts from births to healthcare, education to social services, and politics to housing. Previous scholars have analysed patterns of residential segregation in core neighbourhoods such as Macrolotto 0, San Paolo, and Chiesanuova (Bressan and Radini 2009). Most Chinese migrants experience marginalisation in no small part due to undocumented residency status as well as heavy workloads related to debt incurred from their journey into Europe and the rhythms of fast-fashion work. The political climate also shapes marginalisation. Political speech, such as the 'Italians First' slogan (Poggioli 2020), popular among supporters of right-wing politicians, discursively push migrants to the margins of society. Our research overlapped with the term of Prato's first right-wing mayor (2009-2014), who ran on an anti-immigrant campaign; subsequently, he was defeated by a centre-left candidate, who ran his successful re-election bid in June 2019 on a campaign of love. His council includes the city's first two representatives from the Chinese community. 


\section{'Out of place'}

Urban migration in Europe arguably involves a dominant structure of feeling that can be described as being 'out of place.' The title of our paper offers a play on words with a double meaning. First, the phrase 'out of place' points to the status of migrants as marginal in terms of belonging. Second, the phrase gestures to the fact that our findings come 'out of place' in the sense that data collection and analysis focused on migrant experiences with place. The phrase 'out of place' suggests matter that is misplaced and as such gestures toward a population whose very label as 'migrant' marks them as different from the norm. In this way, migrants are often perceived as 'out of place' in the host society. This may include their legal status as non-citizens or their social status as 'others.' French sociologists have described the immigrant as having a 'double absence,' a condition in which absence is always a flaw that renders the immigrant suspect. Precarious residence, sometimes prolonged indefinitely, contributes to the double absence. Even in cases of documented residence status or full-out naturalisation, the immigrant is 'always an emigrant - absent from the society of origin, and increasingly distant from it in cultural and psychological terms' (Saada 2000, 37). Furthermore, in the host society, the immigrant's outsider status is ever subject to conditional and revocable residency status; full participation in civil society is typically severely limited. In numerous cultural, linguistic, economic, and political ways, the immigrant stands in relation to the born and raised citizen as society's 'other' and thus relatively out of place.

Another meaning of the phrase 'out of place' draws attention to the difficult process that migrants have in terms of building relationships with places in the host society. This stems from not only how they see themselves and their working conditions but how they are seen. Being diasporic, as immigrants, has come to mean being criminalised (Angel-Ajani 2002). Immigrants have come to be associated with occupying Europe's 'new savage slot' (Silverstein 2005). In the case of the Chinese in Prato, whereas they embrace a self-image as hard-working and self-sacrificing, they bear the burden of a reputation as 'deviant,' 'money-obsessed,' and 'ruthlessly exploitative' (Bracci 2012; Dei Ottati and Cologna 2015, 31). Such stereotypes likely constrain Chinese migrants and contribute to their living in stigmatised places, such as factories and Chinatown, thereby limiting the possibilities of knowledge about new places. Everyday forms of racism are widespread (Essed 1991). Not only have markets and supply chains become globalised; witness the globalisation of racism (Herzfeld 2007). Our research exposed people's troubled relationship to place in the context of globalisation.

We anchor this investigation in 'place' for several theoretical and methodological reasons. First, place is among the most fundamental forms of embodied experience and can capture complex emotional, behavioural, and moral relationships between people and the territory in which they live (Feld and Basso 1996). Second, the way people perceive, invest, and discuss specific places can provide important information about one's own points of social interaction and thus access to local knowledge (Kahn 1996). Our approach gestures to the idea of 'places of memory' (Nora 1989, 15 ) as sites where intangible memory and values can be physically observed, sustained, and reproduced through practices and performances (Connerton 1989, 61). Third, we embrace an impulse to induce place-making knowledge in relation to 'diasporic 
heritage' - albeit marginalised, misunderstood, and far beyond authorised heritage discourses (Smith 2006) - to understand the places that migrants found to be meaningful. Introducing a diasporic element troubles and challenges tendencies rooted in nationalist sentiments (Ang 2011; Harrison 2013; Macdonald 2009).

\section{Ethnographic methods: integrating approaches}

The project involved a transnational collaboration that aimed to contribute knowledge, training, and policy applications to understand and confront social dynamics of globalisation. The primary method of investigation was field-based ethnographic research. Team members investigated how individuals, families, and communities become entangled in global supply chains (Tsing 2015) and, in turn, how they cope with the challenges of intensive globalisation (Krause 2018). Broadly, the project asked, How do cultural logics and values persist, collide, or morph in a late capitalist economy anchored in familistic regimes? Data collection consisted of team-based research designed to collect data of three types: (1) unstructured, in the form of ethnographic noticing; (2) structured, in the form of free listing; and (3) semi-structured, in the form of interviewing. A dialectic integration of these forms of data enriched analysis, particularly in terms of experiences that illuminate the embodied ways in which migrants live 'out of place' in the city.

In terms of the unstructured ethnographic data, the author spent 220 days across seven trips between 2012 and 2015 and annual follow-up trips as the project's principal investigator conducting urban ethnographic research at various locations and events across the city, its industrial district, and connected townships. Ethnographic fieldwork incorporated experiences of cultural intimacy through daily encounters with a range of migrationrelated happenings. These included visits to exhibits and theatrical performances, participation in immigration-related conferences and integration events, volunteer shifts in a pizza tent at a summer festival, and attendance at a public funeral that combined evangelical, Buddhist, and secular elements to remember Chinese workers who perished in a tragic fire.

Because of the significant ways in which kinship practices were entangled with the global economy, the author conducted hospital-based ethnography among Italian healthcare professionals and Chinese migrant parents who brought in their infants for threemonth check-ups, which often involved babies born prematurely but not necessarily with serious conditions. Both authors co-facilitated a digital storytelling workshop, which consisted of a heterogenous group of Italians in terms of age, gender, and region of origin, as part of the applied 'action' project 'Neighborhood Plots' (Trame di Quartiere) in collaboration with the Prato-based IRIS research institute. During this time, we felt the gaze of resident Italians as we walked together in the city centre; we noticed signs of far right-wing political parties hostile to immigrants, and became drawn into a charged confrontation between an Italian property owner and Chinese migrant tenants over a housing controversy. These experiences of 'being there' provided us with embodied, first-hand knowledge of the racial tensions in Prato.

In terms of the structured ethnographic data, during a month-long exploratory trip in 2015, the co-author conducted 9 free-list interviews and followed up with several openended questions. The quantitative data produced from free-list interviews allowed us to home in on places that were significant for Chinese migrants in Prato. As such, these 
data provide a systematic lens on framing Chinese migrants' daily interactions with places. Free listing is a powerful technique commonly used to identify the elements and boundaries of a particular domain and determine the salience or importance of words defining the domain (Bernard 2006; Libertino et al. 2012). Free listing is described as a simple and flexible interviewing technique that involves asking participants to list all the words or items associated with a term and then follow up and ask them to define or elaborate on the features of the terms they have provided (Smith et al. 1995; Sutrop 2001; Weller 2015). Quinlan (2005) summarises several assumptions of free listing. First, researchers assume that respondents will list items in order of familiarity. This means that the earlier that respondents list an item, the more familiar it is to them. Second, if a respondent can list more items in a specific cultural domain, they will have more knowledge in that field compared with other respondents who can provide shorter lists. Third, items that most respondents mention will be locally prominent.

Researchers have used free listing to examine a wide range of topics, including illness (Weller 1984), colour (Smith et al. 1995), brands of bicycles (Furlow 2003), ethnobotany (Quinlan 2005), menus across socioeconomic classes (Libertino et al. 2012), spring break experiences (Ribeiro 2012), and quality of life in prisons (Fleisher and Harrington 1998). Even in the context of challenging research projects, such as transactional sex (FieldingMiller et al. 2016) or post-disaster genocide (Bolton and Tang 2004), free-listing is considered a useful method because of its reputation as being relatively easy to implement. Gravlee's (2005) ethnographic study of core emic categories related to racial classification in Puerto Rico illustrates the significance of ambiguity in the everyday experience of skin colour. It indicates that free listing offers cohesive perceptions on colour from respondents, particularly 'how people embrace or obscure such shared meanings of colour to meet different ends in everyday social interaction' (Gravlee 2005, 963). Free listing therefore emerges as a method that uncovers locally meaningful categories that may appear neutral or even invisible in the broader society and, to certain respondents, may be controversial and ambiguous (Bernard and Gravlee 2015).

The number of respondents in existing free-listing studies varies and usually ranges from 20 to 500 (Libertino et al. 2012, 270). Using a small number of participants, as low as 9 but commonly in the range of 20-30, the technique can reveal 'indigenous' categories that are locally meaningful (Bernard and Ryan 2010). In our research, most informants for free listing were recruited based on the author's social and research network from having worked in Prato for nearly two decades and from the co-author's new friendships. Two participants worked in the fast-fashion industry at the time. Two formerly worked in the fast-fashion sector but had changed their occupations to language school teacher and food truck owner. One respondent was a very successful entrepreneur who owned a clothing factory in Prato. The remaining four respondents were second generation Chinese migrants whose occupations were journalist, translator, cultural mediator, and bar owner. These four respondents can all speak both fluent Italian and Chinese. The occupational and class diversity of the pool allowed these participants to provide a broad picture of Chinese migrants in Prato rather than represent depth in terms of garment worker experiences.

The free-list interview protocol began with two prompts about their experiences in the city of Prato: 'List all the places you know in Prato' and 'List all the places you go.' After that, they were asked, 'What are some places you feel safe or comfortable?' And then, 
'What are some places you feel unsafe or uncomfortable?' The questions concluded with a comparison: 'In your hometown in China, what are some places you visit? And what are some of the places you miss most?' The protocol then shifted to open-ended questions: 'What were you doing in the places listed? Why do you feel safe or unsafe in some places? What are some places you wish existed or had access to in Italy?'

In terms of semi-structured data, our team conducted 41 interviews with Chinese parents; some involved both mother and father or one parent and a grandparent. Recruitment occurred via the team's initial research assistant's networks, a local immigration office, as well as a hospital. We conducted twenty-one interviews with Italians, including healthcare professionals and others with a history working in the Made in Italy sector, and we documented eight exam visits for a total of 71 audio recordings. Among our Chinese research participants, two-thirds had experienced living in other cities in Europe or Italy before settling in Prato, suggesting a high degree of mobility. Half of our participants voluntarily disclosed the history of their legal status, and of those, $75 \%$ had at one point been undocumented. Their time spent in Italy ranged from between two and twenty-seven years. Thirtyfour were from Zhejiang Province, one from Hunan, and three from Fujian. Another two were born in Italy. We deferred to participants to decide the language they preferred to speak: Mandarin, Wenzhouese, or Italian. A number of the interviewees preferred their native dialect of Wenzhouese, also the native language of our initial multilingual research assistant. Our team produced transcriptions of all interviews. Audio recordings were transcribed into simplified Chinese or Italian and translated into English. We input the text files into the software MAXQDA to identify themes, develop a codebook, and code interviews (Ryan and Bernard 2003). The co-author, a native Mandarin speaker with U.S. academic training, assisted with translations, codebook development, and coding. Themes fell into several overarching categories, such as the value of going abroad, the value of living in Prato, and the value of working in Prato. Elsewhere, we have analysed findings related to kinship, economy, and care, particularly the ways in which the circulation of children creates global households and also underwrites capitalist value. In this paper, we draw from the theme concerning identity (including citizenship, language, and discrimination) as we shift the focus to specific interactions with place in an urban setting.

\section{Making place-based knowledge: an overview of findings}

In this section, we present the results of our mix of ethnographic methods to generate meaningful data. We show that Chinese migrant interactions with specific places occurred alongside urban marginalisation and discrimination. Generating quantitative data from free-list interviews allowed us to systematically identify the most meaningful places and further explore the wide range of associations with those places. Furthermore, we articulate the quantitative findings with qualitative data, specifically place-based narratives from urban encounters, participant observation, and semi-structured interviews, to highlight challenges with marginalisation and racism.

\section{Quantitative results: contents and boundaries of a cultural domain}

Factory, home, and Chinatown were the three most frequently mentioned places (Figures 1 and 2). These three places clarify the core items belonging to the cultural domain of 


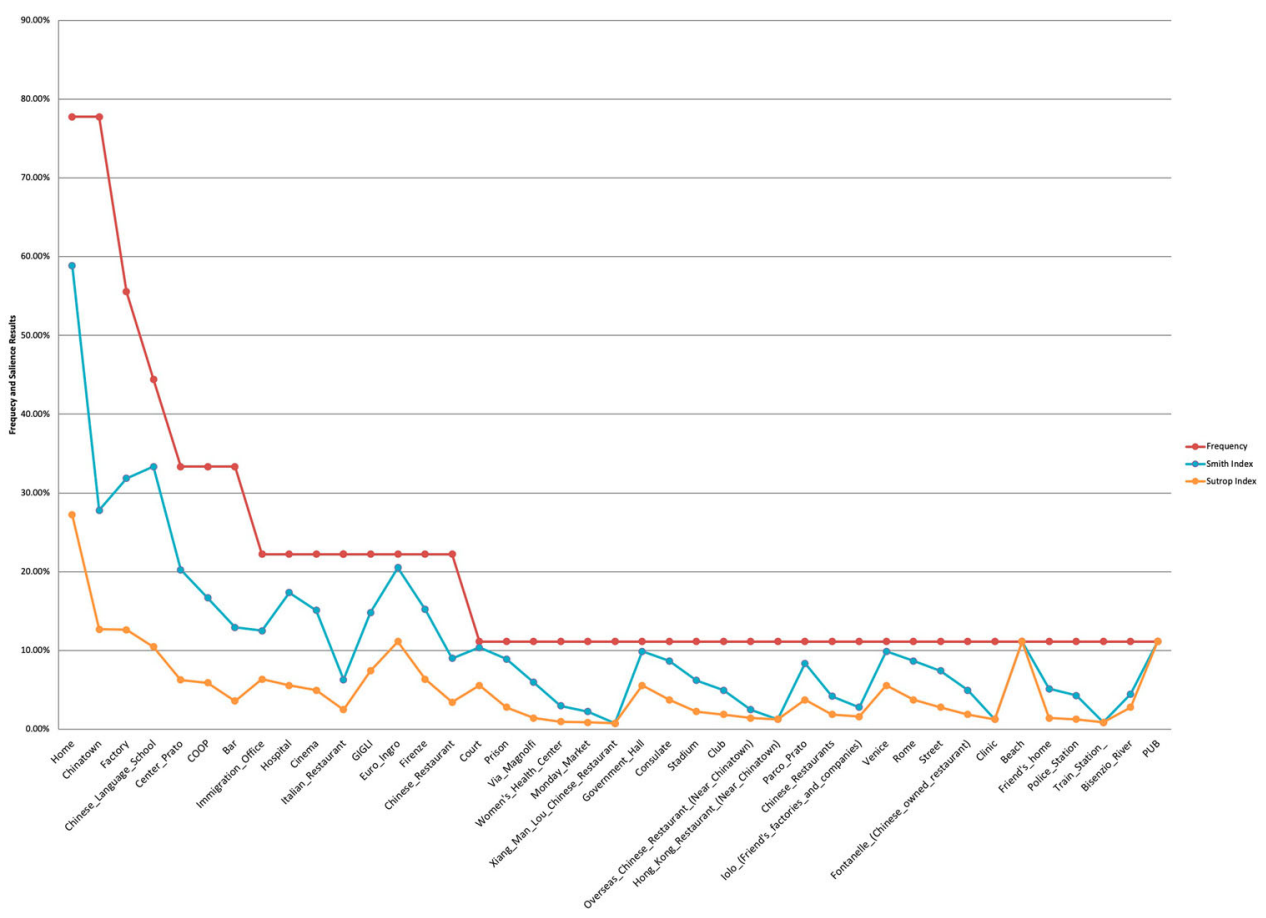

Figure 1. Frequency and Salience Results from Free Listing (in vivo terms).

'place' for Chinese migrants and also indicate their segregated and marginalised lives. These three places are concentrated in neighbourhoods where most Chinese migrants work and live. Such restricted movement across the city implies the boundaries of places as the neighbourhoods where Chinese spend most of their time.

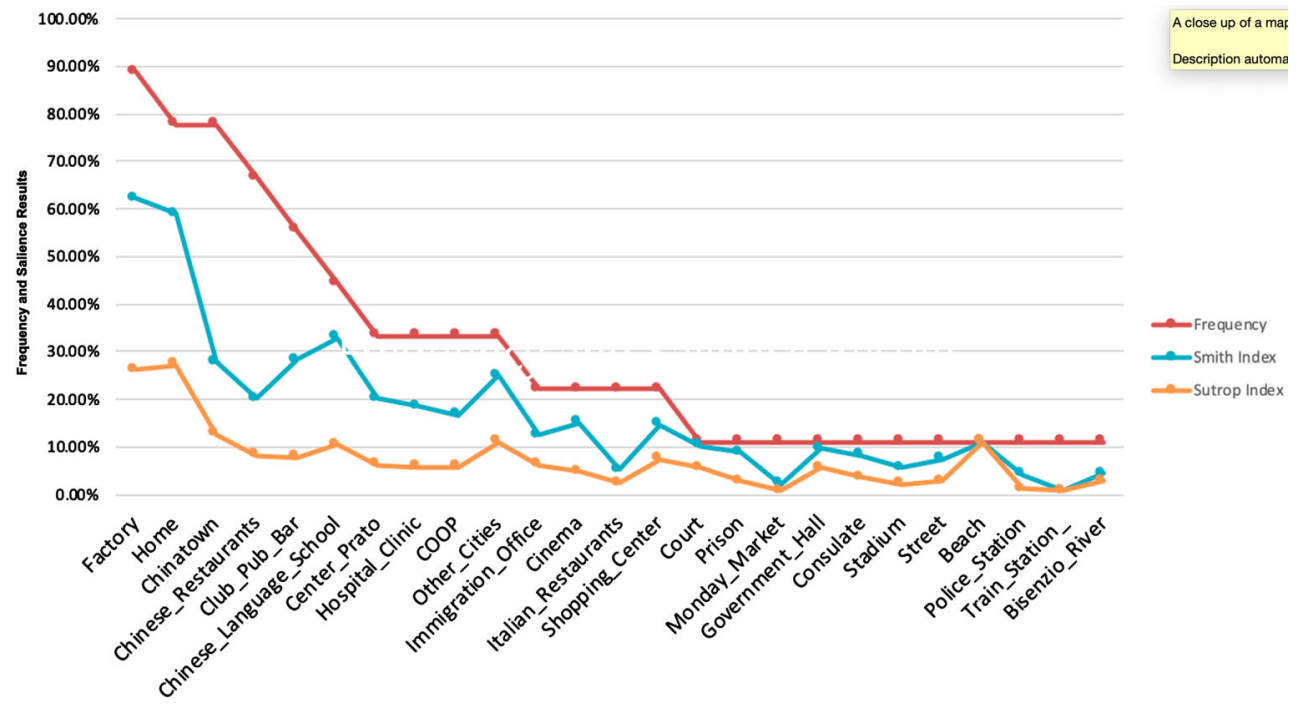

Figure 2. Frequency and Salience Results from Free Listing (in combined terms). 
The places that participants listed were analysed in terms of frequency and cultural salience. Frequency refers to the number of mentions across all lists (Sutrop 2001) and common knowledge or consensus within a given cultural context (Quinlan 2005, 225). Items that are frequently mentioned are assumed to be highly salient to respondents (Smith and Borgatti 1997). The salience index shown in the two figures considers the numbers of respondents who mentioned the item, the average position of the item in the free-listing procedure and the length of each respondent's list. Smith and Borgatti ${ }^{1}$ invented and then Sutrop ${ }^{2}$ modified the calculation of salience. Both calculated the salience based on frequency and mean position (rank score) of an item, but used different formulas to do so.

We used the Add-in FLAME v1.1 in Microsoft Office Excel to perform the quantitative analysis (Borgatti 2015). Participants mentioned names of places in Mandarin or Italian. The co-author retained all the Italian expressions of places, but translated the names spoken in Mandarin into English for analysis and publishing purposes. For example, in Figure 1, COOP, GIGLI, Euro Ingro, Via Magnofi, Parco, lolo, and Bisenzio are kept in their Italian expression, while others like factory, market, Chinese restaurant, consulate, stadium, etc, were translated from Mandarin at the very beginning. One finding was that the participants mentioned all Italian local places in Italian and other Chinese places such as Chinese restaurants or factories in Chinese.

We ran the analysis twice. The first time, we used all 41 non-overlapping items and obtained the results in Figure 1. Since various lists may contain different phrasings of the same concept, it is common for researchers to standardise concepts (Quinlan 2005, 229). The second time, we combined similar terms into overarching categories, and this resulted in 25 places. For example, the co-author combined different Chinese restaurants listed by different respondents into one term named 'Chinese restaurants.' The co-author also combined different shopping destinations, such as GIGLI and Parco Prato, into one term labelled 'shopping center.' These combinations yielded the results shown in Figure 2.

The term factory was mentioned by most respondents and had the highest salience (Figure 2). The high salience of 'factory' indicates its important local meanings and value. Practically, it is an essential category of place where many Chinese migrants spent most of their days and nights working and living. Some respondents listed 'factory' as an unsafe place because substandard safety conditions could cause deadly fires, such as the tragic Teresa Moda fire in Prato that killed seven Chinese migrants (Krause and Bressan 2014). Emotionally, this is also the place where Chinese people experienced the bitterness and oppression associated with unexpected long hours of labour and sacrifices of care for themselves or their children. When respondents mentioned factory, they expressed the attitude that factory is a place where they should stay and can only stay, because that is why they go abroad. Therefore, 'factory' is both an important place for earning money and accomplishing goals of entrepreneurial success as well as a place heavily limiting their activities and producing many traumatic and unsettling memories.

Our research deepens the contrasts of the meanings of factories as a place and identifies a highly meaningful indigenous term. One participant, who claimed to be the city's first owner of a Chinese business, described the specific ways in which Chinese migrants build connections with factories as an indication of 'spiritual insistence' - an unwavering determination to become entrepreneurs and own their business regardless of size. Although initially most workers cannot make much money when they work in small 
workshops, as time goes on they may work even harder, because of spiritual insistence, in hopes of becoming their own boss someday. They desire the role not for the ability to be bossy but for the essence of autonomy that being a boss promises: the right to decide what they want to do and how to do it. All told, this pursuit translates into proving their worth as overseas migrants. The self-sacrifice reflects the ideology of ' $d u o$ lao $d u o d e$ - 'if you work more, you should earn more.' The saying's origins trace to Deng Xiaoping's economic reforms starting in the late 1970s, a period in China famous for opening to a market economy and encouraging people to work hard and earn what they want no matter what it takes. The famous 'Cat Theory' during that time, 'No matter it's black cat or white cat, it's a good cat if it could catch a mouse,' proposed the value of working hard and getting a job done. It also encouraged dynamic and creative individual and collective participation into the enriching market activities. People in Wenzhou became especially known for transforming themselves from poor peasants and defiant traders to ultimate capitalists known for popular religion and ritual expenditure (Yang 2000). On the one hand, 'factory' represents the exploitative working mode that usually relates to Chinese migrants' simple pursuit of money and signifies their experiences of marginalisation and isolation. On the other hand, 'factory' also expresses Chinese migrants' chase for entrepreneurial value underwritten by a spirit of hard work and determination regardless of challenging circumstances.

Another place with high salience, 'Chinatown,' also showed intra-variation from freelisting data (Bernard and Ryan 2010, 181). When different respondents mentioned 'Chinatown,' they expressed contrasting attitudes and emotions. For some, it indicates a place with small cut-and-sew workshops and shabby living circumstances. It signals a place that is embarrassing due to the shameful associated experiences and memories. For others, it is the only place where they can 'smell the taste of China' and situate their memories back in China. Chinatown becomes such a place that is immersed in bitterness and insecurity but also sweetness and longing.

Besides focusing on the places that have both high frequency and high salience, it is critical to pay attention to places with low frequency but high salience. For example, in Figure 2, 'Chinese Language School,' with lower frequency, was mentioned only 4 times across all interviews, has even higher salience compared with 'Chinatown.' This indicates that when respondents mentioned 'Chinese Language School' they usually mentioned it earlier in their list. The same situation applies to other places, like 'other cities,' 'cinema,' 'shopping center,' and 'beach.' These items expand the diversity of places Chinese migrants have access to or have built relations with. It illustrates how Chinese migrants, typically considered as an isolated and marginalised population, can possibly share many outlooks with the host communities, such as valuing family reunion time, enjoying different types of entertainment, and pursuing relaxation after work. Such diversity relates to differences of occupation, migration experience, age, and other factors among respondents. These data are unexpected. On the one hand, they show how Chinese migrants are not always restricted in factories and Chinatown. On the other hand, they reveal how Chinese migrants may be actively engaging with places in ways that are not immediately evident. This finding adds nuance to understandings of marginalisation.

Another unexpected aspect of the free-listing process was the emotional response especially when the participant was unable to list very many places. The concept of place in most Chinese migrants' minds turned out not to be simple and neutral, but 
rather a very controversial topic that provoked embarrassment, awkwardness, and even sadness. There were silent moments between the interviewer and interviewee during the process of asking and answering free-listing questions. The questions that asked about places they usually go or know provoked most respondents to say something like, 'Places ... I did not go to any place ... What place ... ?' They seemed confused, even disoriented, about questions of 'place' and also felt embarrassed for not being able to respond to those questions with many place names. The confusion about place led the participants to question the questions. One participant suggested the questions about place were too personal; another commented that places that they go should not matter since no place belonged to them. The interactions became saturated with awkwardness and embarrassment. The forces behind these emotions and encounters should not be overlooked but rather need to be understood and interpreted (Behar 1996; Ceglowski 2000; Emerald and Carpenter 2015; Rosaldo 1989). Co-presence and experiential encounters (Borneman and Hammoudi 2009) can become a significant source of knowledge that makes possible a transformation of what we know, in this case, about diaspora, place, and migrants. Encounters that were full of silence, awkwardness, and confused feelings between researcher and participant illustrate the complex meanings of 'place' and of being 'out of place.'

\section{Qualitative results: 'we are not made of air' and other place-based narratives}

Semi-structured interviews and ethnographic encounters deepen our findings related to place. They highlight everyday forms of racism and marginalisation. We recorded numerous signs of racism in our field notes: anti-racist graffitti was scrawled on walls along trafficked boulevards; anti-immigrant slogans appeared on doorfronts of right-wing political party offices; anti-Chinese discourses circulated in public forums and private conversations. In contrast, we attended exhibits and events that signalled a range of political approaches to integration. Below, we draw on participant narratives that underscore racialized hardship whether in the context of public or private places. The first narrative pertains to housing and racial tensions between neighbours. The second and third narratives also relate to housing but suggest contrasting experiences between newcomers and longtime residents. The fourth narrative shifts to a public space and offers an account of institutional racism.

Fen had just moved into her apartment in Prato when her Italian neighbour from the unit below showed up to complain. 'The foreigner [Italian] from downstairs deliberately persecutes Chinese people, and he thinks Chinese people often make noise. If I move a little bit or make noise, for example, the sounds of walking or the sound of things dropping on the floor, he would hear it and he would come upstairs and complain that it's too noisy. He has called the police as well.' Fen admitted that moving created some noise but also defended herself:

It was loud, carrying boxes and things, and he came upstairs. He said it's loud upstairs because we are moving things here and there. We said that we are human beings and we are not made of air, we have to make noise, right? So after that, he didn't complain about it that often.

Fen's comeback of 'we are human beings, and we are not made of air' demonstrates a keen awareness of the dehumanising experiences that many Chinese migrants expressed related 
to their quotidian experiences of discrimination and marginalisation in Prato. Such experiences align with the standard definition of marginalisation: being relegated to an unimportant or powerless position within society (Webster's Dictionary). Participants commonly described Prato as a uniquely harsh social environment based on having lived in other cities in Europe. Fen's pushback enacts an assertion that her interlocutor recognises her as a human being; to be human involves having a physical body and therefore making noise is inevitable. In essence, this statement, which she repeats in the interview a second time, suggests that she realises the power of boldly asserting her humanity. Asked whether she felt that it happened in other places she had lived, she responded, 'Only in Prato. It's because there are many Chinese people in Prato that annoy him.'

In other ways that underscore class differences, what might normally be considered a private place of relaxation and rejuvenation, the place typically called 'home' represented an ambiguous category. Zou, a middle-aged woman who can barely speak Italian and had worked in the fast-fashion industry for five years, said,

We workers cannot compare to the bosses, we don't have cars and houses ... we live in a single room with two beds squeezed together. There is no feeling of home here. It is uneasy and tough to live here for people like us. We can only ride a bicycle when we need to go out there. We also don't have time to go to those places because we don't have breaks during the Chinese festivals... If my daughter would visit me, I would feel embarrassed.

For her, the place where she rests cannot be called home because of a lack of a feeling of home. She described the space as cramped, anything but cozy. She went on to talk about how there was nothing that belongs to her, neither the room nor the furniture. Furthermore, in revealing that she did not have her family with her, she implied that it was anything but a place of intimacy. The culturally prominent place of home, therefore, for many migrants has come to mean loneliness and an unsettled sense of social marginality.

By contrast, another Chinese migrant who moved to Prato when she was small and grew up there listed home in a very positive way. She described home as a very safe, comfortable, and relaxing place. Xiao is the second generation of Chinese migrants who speaks fluent Chinese and Italian. She has worked as a translator in prisons, hospitals, language schools, and immigration offices. Such contrasting expressions of home from Zou and Xiao indicate their different life experiences of being migrants, including their ages, residence status, occupations, and capability of speaking Italian. Their different perceptions of 'home' not only uncover the physical differences of their homes but also suggest the social relationship they can build within their homes.

A number of Chinese parents endured discrimination as they sought to obtain legal documents for their infants and children. One mother's story was especially poignant. It speaks to a sense that authorities treated Chinese people differently from other migrants. The mother, Hui-Li, recalled that her son would have been around 3 months old at the time, a milestone that triggered a requirement to obtain a residence permit required of non-citizens. Migrants in Prato had to present themselves and their children in person at the police station, and this legal rite commonly involved waiting in long lines. Hui-Li recalls that it was early January, and the weather was cold, wet, and windy:

We needed to go to the police station to get the residence [permit]. We needed to go there at $7 \mathrm{am}$ and wait in line. No matter if it was rainy or windy, there was no place to hide [from the 
elements], we just waited there. That day, I was afraid that my son felt cold, because he was just 2 or 3 months old.

Hui Li had a vivid memory of searching for protection from the cold, especially for her baby. She left her place in line on the side of the road, walked into a hallway, and then out into a garden. She took cover under a roof where a security guard and some other migrants were also standing.

Some Black people held their children, also Romanian people, other foreigners, but no Chinese people.... Two security guards were standing there, looking at me as I walked towards the roof with my baby. Right away, the policeman pushed me out.... He asked me to stand in the line outside, but I said the wind outside was strong, and there was rain outside. I said it was ok for an adult, but my child was just 2 months old ... it was not ok for the child. I said that they could stay here [meaning the other foreigners]. I also wanted to stay here for a while. He directly pushed me out, pushed me out ... I said to him 'Why could they stay there? Why couldn't we Chinese people stay there?' Later, there was a line outside, one line, about 30-40 people, all Chinese people, started to yell and shout, then the gate guard, the security guard, saw the situation and went inside. Another guy went out and said: 'Ok, you can stand here, but don't make any noise.'

The final part of the exchange between the mother, Hui-Li, and our team's research assistant, Fangli, conveys a strong sense of emotion in the interaction as the interviewer seeks clarification regarding the sequence of events to make sure she understood correctly how poorly the mother had been treated:

Fangli: He did not let you in

Hui-Li: Right, just let me stand there.

Fangli: Just let you stand there?

Hui-Li: From this example, you can see how people from other countries can stand there and hide in the rain and wind?!

Fangli: Are you talking about the police station of Prato?

Hui-Li: Right, we Chinese people hold an infant, like 3 months old, cannot stand there.

Fangli: They let you stand there after the yelling outside, right?

Hui-Li: Right, right right, this is real discrimination.

Fangli: Right, right, right, that's hard, my tears almost come out.

Hui-Li: God, then I told him...

Fangli: Thinking about this, I almost want to cry.

Hui-Li: Right, I told him, I can be cold, that's fine, but I'm not doing this for myself. As a mother, as a mother, I mean my child was frozen, how hard would that be for a mother?

This story speaks to a mother's awareness of and resistance to institutional racism. The last statement of her story - that she was finally given permission to stand under the roof on the condition she 'not make any noise' - echoes the opening of this section in which Fen asserts the right to make noise as a human being. In this account of the conditions for seeking a residence permit, the mother is asserting her fundamental human right to exist. In this sense, it represents a small but significant everyday form of resistance, on behalf of her child, against a powerful state institution.

Taken together, the ethnographic narratives offer a range of experiences that speak to place-based marginalisation. Migrants experience marginalisation across places, whether public or private. Forms of resistance to being marginalised and discriminated against in these accounts appear in small moments. Although in themselves they are not the 
stuff of social movements, they nevertheless represent a keen awareness of unfair treatment based on racial differences in a globalised urban context.

\section{Discussion: migrants in place}

'Place' stirs up feelings of longing and belonging related to migrants' marginal status in the globalised factory-city of Prato. We integrate quantitative and qualitative data to enrich understandings of place. We learn that 'place' is understood among Chinese migrants as a concept full of power relations and inequality as well as promise and potential. Encounters between participants and researchers transform traditional understandings of how migrants experience place. Locally significant meanings and values of place are not only reflected in individual experiences and stories but also entangled in the hegemony of global supply chains. Place-based meanings show how places assumed to be neutral are deeply charged and point to another reality: that migrants make meaning from places of marginalisation. Creating unique meanings and building new relationships challenge assumptions of double absence. We argue that migrants are actually in place. Migrant narratives indicate how - despite everyday forms of racism that attempt to render them as absent as still air - they resist through asserting their presence.

We have suggested the stakes of producing and transforming knowledge connected to marginalisation, racism, and resistance among a diasporic population. Local voices and narratives reveal knowledge about the ways in which Chinese migrants conceptualise 'place' as both physical involving different activities, and mental embodying experiences, memories, and identities. These forms of knowledge might be shared with public institutions, building on past initiatives. The 2015 exhibit Facewall Prato at the Museo del Tessuto (Textile Museum) featured video and photography installations of diverse encounters among migrants and Italian residents, and walking across piazzas during our fieldwork we passed public displays of posters that promoted ' 100 possible interwoven worlds' (Figure 3). ${ }^{3}$ Such initiatives create a place for migrant experiences to be recognised and understood to further challenge their 'double absence.' Furthermore, the tragic 2013 fire intensified health and safety inspections and thus fewer migrants may now be living and working in the same places. As circumstances change, research such as this nevertheless documents a significant moment in a community's history that is worth recognising and remembering.

Chinese migrants are in the process of building new relationships with a range of places and adding complexity to the notion of 'out of place.' Respondents' different occupations, migration experiences, and social status complicate their encounters with marginalisation and discrimination. A limitation of our research was a lack of comparison between groups, such as Chinese and African migrants. Stratification among migrants diversifies forms of resistance to racism and discrimination in Italian society. That said, increasing numbers of local associations, successful entrepreneurs, and activists have been taking advantage of their language capabilities, wealth, and social networks to be active on social media and appear on TV shows as well as at public events to create platforms for recognition and to build solidarity. Through future collaborations with public institutions, local associations, and migrant representatives, the findings of this research can enrich understandings of the idea of 'out of place,' and open space for migrants to be 'in place' in both practice and principle. 


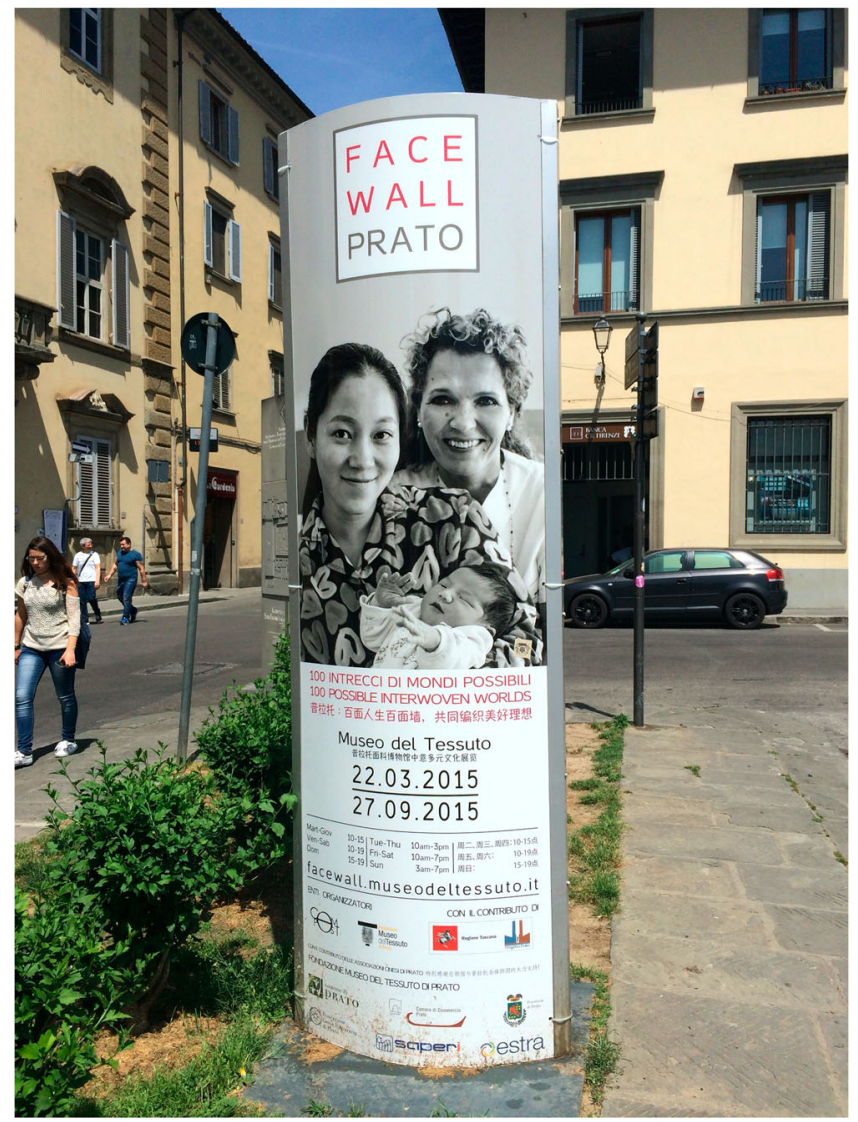

Figure 3. A poster in Piazza San Francesco publicises the Facewall Prato exhibit. Photo by Ying Li, June 2015.

\section{Notes}

1. Smith and Borgatti (1997): $S=\left(\left(\sum\left(L_{i}-R_{j}+1\right)\right) L_{i} / N_{\text {., }} L_{i}\right.$ : the length of a list $i$; $R_{j}$ : the rank of item $j$ in the list; $N$ : the number of the list.

2. Sutrop (2001): $S=F /\left(N_{m} P\right) ; F$ : frequency; ${ }_{m} P$ : mean position.

3. See also the museum archive, https://www.museodeltessuto.it/facewall/.

\section{Acknowledgments}

We are grateful to other members of our research team, especially Massimo Bressan for his ongoing collaboration and support from the Prato-based IRIS research institute. Research assistance from Fangli Xu and Xioayun Liao were essential to data collection. We benefitted greatly from feedback on an earlier version of this paper from members of the Migration Working Group at the University of Massachusetts Amherst, particularly co-conveners Scott Blinder and Rebecca Hamlin as well as participants Rodrigo Dominguez-Villegas, Ina Ganguli, Marielos Arlen Marin, Joya Misra, Ide O'Carroll, and Jenny Withrow. We are grateful to the JEMS editorial staff and three anonymous reviewers for their constructive comments on earlier drafts of this paper. We are indebted to the people in Prato who contributed directly to this research, particularly the dozens of migrants who shared their stories and experiences with us. 


\section{Disclosure statement}

No potential conflict of interest was reported by the author(s).

\section{Funding}

This work received support from the National Science Foundation for the senior research project 'Chinese Immigration and Family Encounters in Italy' (BCS-1157218) and Cultural Anthropology Research Experience for Graduates (REG) Supplement, 'Diasporic Heritage and Overseas Chinese'; a Wenner-Gren Foundation International Collaborative Research Grant, (ICRG-114), 'Tight Knit: Familistic Encounters in a Fast-Fashion District'; and a residential fellowship from the National Humanities Center.

\section{References}

Ang, len. 2011. "Unsettling the National: Heritage and Diaspora." In Heritage, Memory \& Identity, edited by Helmut Anheier and Yudhishthir Raj Isar, 82-94. London, US: Sage.

Angel-Ajani, Asale. 2002. "Diasporic Conditions: Mapping the Discourses of Race and Criminality in Italy." Transforming Anthropology 11 (1): 36-46.

Becattini, Giacomo. 2001. The Caterpillar and the Butterfly: An Exemplary Case of Development in the Italy of the Industrial Districts. Florence: Felice Le Monnier.

Behar, Ruth. 1996. The Vulnerable Observer: Anthropology That Breaks Your Heart. Boston, MA: Beacon Press.

Bernard, H. Russell. 2006. Research Methods in Anthropology: Qualitative and Quantitative Approaches. 4th ed., 301-305. Lanham, MD: Altamira.

Bernard, H. Russell, and Clarence C. Gravlee. 2015. "Introduction." In Handbook of Methods in Cultural Anthropology, edited by H. Russell Bernard and Clarence C. Gravlee, 1-20. Lanham, MD: Rowman \& Littlefield Publishers.

Bernard, H. Russell, and Gery W. Ryan. 2010. Analyzing Qualitative Data: Systematic Approaches. Los Angeles: Sage.

Bolton, Paul, and Alice M. Tang. 2004. "Using Ethnographic Methods in the Selection of PostDisaster, Mental Health Interventions." Prehospital and Disaster Medicine 19 (01): 97-101.

Borgatti, Stephen P. 2015. "Software Review: FLAME (Version 1.1)." Field Methods 27 (2): 199-205.

Borneman, John, and Abdellah Hammoudi. 2009. Being There: The Fieldwork Encounter and the Making of Truth. Berkeley: University of California Press.

Bracci, Fabio. 2012. “The 'Chinese Deviant': Building the Perfect Enemy in a Local Arena." In No Borders: Immigration and the Politics of Fear, edited by E. Bell, 97-116. Chambéry: Université de Savoie.

Brandi, Enrico, and Andrea Sabatini, eds. 2012. "Dossier Statistico Sociale 2012". Osservatorio Sociale ed Ufficio Statistica della Provincia di Prato.

Bressan, Massimo, and Sabrina Tosi Cambini. 2009. "The 'Macrolotto 0' as a Zone of Transition: Cultural Diversity and Public Spaces." In Living Outside the Walls: The Chinese in Prato, edited by Graeme Johanson, Russell Smyth, and Rebecca French, 149-160. Newcastle upon Tyne, UK: Cambridge Scholars Publishing.

Bressan, Massimo, and Massimiliano Radini. 2009. "Diversity and Segregation in Prato." In Living Outside the Walls: The Chinese in Prato, edited by Graeme Johanson, Russell Smyth, and Rebecca French, 130-148. Newcastle upon Tyne, UK: Cambridge Scholars Publishing.

Camera di Commercio. 2020. L'imprenditoria straniera in provincia di Prato, Rapporto 2019, Sintesi dei risultati. Prato: Camera di Commercio.

Ceglowski, Debroah. 2000. "Research as Relationship.” Qualitative Inquiry 6 (1): 88-103.

Chen, Calvin. 2015. "Made in Italy (by the Chinese): Migration and the Rebirth of Textiles and Apparel.” Journal of Modern Italian Studies 20 (1): 111-126. 
Clean Clothes Campaign. 2014. Tailored Wages: Are the Big Brands Paying the People Who Make Our Clothes Enough to Live On? https://cleanclothes.org/livingwage/tailoredwages/tailored-wage-report-pdf.

Collyer, Michael, and Hein de Haas. 2012. "Developing Dynamic Categorisations of Transit Migration.” Population, Space and Place 18 (4): 468-481.

Connerton, Paul. 1989. How Societies Remember. Cambridge and New York: Cambridge University Press.

Crawley, Heaven, and Dimitris Skleparis. 2018. "Refugees, Migrants, Neither, Both: Categorical Fetishism and the Politics of Bounding in Europe's 'Migration Crisis'." Journal of Ethnic and Migration Studies 44 (1): 48-64.

Dei Ottati, Gabi, and Daniele Brigadoi Cologna. 2015. "The Chinese in Prato and the Current Outlook on the Chinese-Italian Experience." In Chinese Migration to Europe: Prato, Italy and Beyond, edited by Loretta Baldassar, Graeme Johanson, Narelle McAuliffe, and Massimo Bressan, 29-48. New York: Palgrave Macmillan.

Emerald, Elke, and L. Carpenter. 2015. "Vulnerability and Emotions in Research: Risks, Dilemmas, and Doubts." Qualitative Inquiry 21 (8): 741-750.

Entwistle, Joanne. 2000. The Fashioned Body: Fashion, Dress, and Modern Social Theory. Malden, MA: Blackwell.

Essed, Philomena. 1991. Understanding Everyday Forms of Racism: An Interdisciplinary Theory. Newbury Park: Sage Publications.

Feld, Steven, and Keith H. Basso. 1996. "Introduction.” In Senses of Place, edited by Steven Feld and Keith H. Basso, 3-12. Santa Fe, NM: School of American Research Press.

Fielding-Miller, Rebecca, Kristin L. Dunkle, Hannah L.F. Cooper, Michael Windle, and Craig Hadley. 2016. "Cultural Consensus Modeling to Measure Transactional Sex in Swaziland: Scale Building and Validation." Social Science \& Medicine 148: 25-33.

Fleisher, Mark S., and Jennifer A. Harrington. 1998. "Freelisting: Management at a Women's Federal Prison Camp." In Using Methods in the Field: a Practical Introduction and Casebook, edited by V. C. De Munck, and E. J. Sobo, 69-84. Walnut Creek, CA: AltaMira Press.

Foucault, Michel. 1980. Power/Knowledge: Selected Interviews and Other Writings 1972-77. Edited by C. Gordon. New York and London: Harvester Wheatsheaf.

Furlow, Christopher. 2003. "Comparing Indicators of Knowledge within and between Cultural Domains.” Field Methods 15 (1): 51-62.

Gravlee, Clarence C. 2005. "Ethnic Classification in Southeastern Puerto Rico: The Cultural Model of 'Color." Social Forces 83 (3): 949-970.

Harrison, Rodney. 2013. Heritage: Critical Approaches. Milton Park: Routledge.

Herzfeld, Michael. 2007. "Small-Mindedness Writ Large: On the Migrations and Manners of Prejudice." Journal of Ethnic and Migration Studies 33 (2): 255-274.

Istat, (Istituto Nazionale di Statistica). 2020. Bilancio Demografico Nazionale. https://www.istat.it/ it/archivio/245466.

Kahn, Miriam. 1996. "Your Place and Mine: Sharing Emotional Landscapes in Warmira, Papua New Guinea." In Senses of Place, edited by Steven Feld and Keith H. Basso, 167-196. Santa Fe, NM: School of American Research Press.

Krause, Elizabeth L. 2018. Tight Knit: Global Families and the Social Life of Fast Fashion. Chicago: University of Chicago Press.

Krause, Elizabeth L., and Massimo Bressan. 2014. "Slow Rites, Fast Wrongs.” Truthout.org, July, http://truth-out.org/opinion.

Krause, Elizabeth L., and Massimo Bressan. 2018. "Circulating Children, Underwriting Capitalism: Chinese Global Households and Italian Fast-Fashion." Current Anthropology 59 (5): 572-595.

Krause, Elizabeth L., and Massimo Bressan. 2020. A Disease Origin Story. Vestoj: The Platform for Critical Thinking on Fashion. http://vestoj.com/a-disease-origin-story/. April 21.

Lan, Tu. 2015. "Industrial District and the Multiplication of Labour: The Chinese Apparel Industry in Prato, Italy." Antipode 47 (1): 158-178.

Libertino, Luciano M., Daniela C. Ferraris, M.M. López Osornio, and Guillermo Hough. 2012. "Analysis of Data from a Free-Listing Study of Menus by Different Income-Level Populations.” Food Quality and Preference 24 (2): 269-275. 
Macdonald, Sharon. 2009. Difficult Heritage: Dealing with the Nazi Past in Nuremberg and Beyond. London: Routledge.

Nora, Pierre. 1989. "Between Memory and History: Les Lieux de Mémoire." Representations 26: 724. Special Issue: Memory and Counter-Memory.

Pandolfi, Mariella. 2007. "Memory within the Body: Women's Narrative and Identity in a Southern Italian Village." In Beyond the Body Proper: Reading the Anthropology of Material Life, edited by Margaret Lock, and Judith Farquhar, 451-458. Durham: Duke University Press.

Piore, Michael J., and Charles F. Sabel. 1986. The Second Industrial Divide: Possibilities for Prosperity. New York: Basic Books.

Poggioli, Silvia. 2020. "Regional Elections In Italy: Can The 'Sardines' Win Against Populism?" National Public Radio, January 25. Accessed January 28, 2020. https://www.npr.org/2020/01/ 25/799327929/regional-elections-in-italy-can-the-sardines-win-against-populism.

Quinlan, Marsha. 2005. "Considerations for Collecting Freelists in the Field: Examples from Ethnobotany.” Field Methods 17 (3): 219-234.

Raffaetà, Roberta, and Loretta Baldassar. 2015. "Spaces Speak Louder Than Words: Contesting Social Inclusion through Conflicting Rhetoric about Prato's Chinatown.” In Chinese Migration to Europe: Prato, Italy and Beyond, edited by Loretta Baldassar, Graeme Johanson, Narelle McAuliffe, and Massimo Bressan, 119-137. New York: Palgrave Macmillan.

Reinach, Simona Segre. 2005. "China and Italy: Fast Fashion Versus Prêt à Porter. Towards a New Culture of Fashion.” Fashion Theory: The Journal of Dress, Body \& Culture 9 (1): 43-56.

Ribeiro, Nuno Felipe. 2012. "Using Concomitant Freelisting to Analyze Perceptions of Tourism Experiences." Journal of Travel Research 51 (5): 555-567.

Rofel, Lisa, and Sylvia Yanagisako. 2019. Fabricating Transnational Capitalism: A Collaborative Ethnography of Italian Chinese Global Fashion. Durham: Duke University Press.

Rosaldo, Renato. 1989. Culture \& Truth: The Remaking of Social Analysis. Boston: Beacon Press.

Ryan, Gery W., and H. Russell Bernard. 2003. "Techniques to Identify Themes." Field Methods 15 (1): 85-109.

Saada, Emmanuelle. 2000. “Abdelmalek Sayad and the Double Absence: Toward a Total Sociology of Immigration.” French Politics, Culture \& Society 18 (1): 28-47.

Secchi, Bernardo. 1996. Laboratorio Prato PRG. Firenze: Alinea.

Silverstein, Paul. 2005. "Immigrant Racialization and the New Savage Slot: Race, Migration, and Immigration in the New Europe." Annual Review of Anthropology 34: 363-384.

Smith, Laurajane. 2006. Uses of Heritage. New York: Routledge.

Smith, J. Jerome, and Stephen P. Borgatti. 1997. "Salience Counts-And So Does Accuracy: Correcting and Updating a Measure for Free-List-Item Salience." Journal of Linguistic Anthropology 7 (2): 208-209.

Smith, J. Jerome, Louanna Furbee, Kelly Maynard, Sarah Quick, and Larry Ross. 1995. "Salience Counts: A Domain Analysis of English Color Terms.” Journal of Linguistic Anthropology 5 (2): 203-216.

Sutrop, Urmas. 2001. "List Task and a Cognitive Salience Index.” Field Methods 13 (3): 263-276.

Ticktin, Miriam. 2011. Casualties of Care: Immigration and the Politics of Humanitarianism in France. Berkeley: University of California Press.

Tsing, Anna Lowenhaupt. 2015. The Mushroom at the End of the World: On the Possibility of Life in Capitalist Ruins. Princeton: Princeton University Press.

Ufficio di Statistica del Comune di Prato. 2019. "Analisi della popolazione residente straniera al 31 dicembre 2019.” http://statistica.comune.prato.it.

Weller, Susan C. 1984. "Cross-Cultural Concepts of Illness: Variation and Validation.” American Anthropologist 86 (2): 341-351.

Weller, Susan C. 2015. "Structured Interviewing and Questionnaire Construction." In Handbook of Methods in Cultural Anthropology, edited by H. Russell Bernard and Clarence C. Gravlee, 343390. Lanham, MD: Rowman \& Littlefield.

Yang, Mayfair Mei-hui. 2000. "Putting Global Capitalism in Its Place: Economic Hybridity, Bataille, and Ritual Expenditure.” Current Anthropology 41 (4): 477-509. 